This item was submitted to Loughborough's Research Repository by the author.

Items in Figshare are protected by copyright, with all rights reserved, unless otherwise indicated.

\title{
Can subjective comfort be used as a measure of plantar pressure in football boots?
}

PLEASE CITE THE PUBLISHED VERSION

http://dx.doi.org/10.1080/02640414.2016.1206661

PUBLISHER

(C) Taylor \& Francis

VERSION

AM (Accepted Manuscript)

\section{PUBLISHER STATEMENT}

This work is made available according to the conditions of the Creative Commons Attribution-NonCommercialNoDerivatives 4.0 International (CC BY-NC-ND 4.0) licence. Full details of this licence are available at: https://creativecommons.org/licenses/by-nc-nd/4.0/

\section{LICENCE}

CC BY-NC-ND 4.0

\section{REPOSITORY RECORD}

Kryger, Katrine Okholm, Vicky Jarratt, Sean R. Mitchell, and Stephanie E. Forrester. 2019. "Can Subjective Comfort Be Used as a Measure of Plantar Pressure in Football Boots?". figshare.

https://hdl.handle.net/2134/22412. 
Journal of Sports Sciences, 2016

http://dx.doi.org/10.1080/02640414.2016.1206661

\title{
Can subjective comfort be used as a measure of plantar pressure in football boots?
}

\author{
Katrine Okholm Kryger ${ }^{1,2}$ Vicky Jarratt $^{1}$, Séan Mitchell ${ }^{1,2}$ \& Steph Forrester ${ }^{1,2}$ \\ ${ }^{1}$ Wolfson School of Mechanical and Manufacturing Engineering, Loughborough University, \\ Loughborough LE11 3TU, UK \\ ${ }^{2}$ Sports Technology Institute, Loughborough University, Loughborough, LE11 3TU, UK
}

\begin{abstract}
Purpose: Comfort has been shown to be the most desired football boot feature by players. Previous studies have shown discomfort to be related to increased plantar pressures for running shoes which, in some foot regions, has been suggested to be a causative factor in overuse injuries. This study examined the correlation between subjective comfort data and objective plantar pressure for football boots during football specific drills.

Methods: Eight male university football players were tested. Plantar pressure data were collected during four football specific movements for each of three different football boots. The global and local peak pressures based on a ninesectioned foot map were compared to subjective comfort measures recorded using a visual analog scale for global discomfort and a discomfort foot map for local discomfort.

Results: A weak $\left(r_{s}=-0.126\right)$ yet significant $(p<0.05)$ correlation was shown between the peak plantar pressure experienced and the VAS rated comfort. The model only significantly predicted $(p>0.001)$ the outcome for two (medial and lateral forefoot) of the nine foot regions.

Conclusions: Subjective comfort data is not a reliable measure of increased plantar pressures for any foot region. The use of plantar pressure measures is therefore needed to optimise injury prevention when designing studded footwear.
\end{abstract}

Keywords: Soccer, Discomfort, Tekscan, Foot sensitivity, Visual analog scale

\section{INTRODUCTION}

Comfort is an important factor for footwear in physical activities. Footwear comfort can be related to the fit, aesthetics, passive support and dynamic stability of the shoe, as well as muscle work to stabilise the foot, fatigue, mobility, and alignment of the lower limb (Miller et al., 2000; Mündermann et al., 2001; Nigg et al., 1999; Reinschmidt and Nigg, 2000; Williams and Nester, 2006). Comfort has previously been described as an ever-changing individual perception influenced by mechanical, neurophysiological, and psychological factors (Chen et al., 1995; Miller et al., 2000; Mündermann et al., 2001; Nigg et al., 1999).

Football boots are usually lightweight to help in optimising in-game performance e.g. to allow lower fatigue due to the large distances covered. Compared to running shoes, no cushioning support is provided, the outsole studs distribute pressures differently and the soles are usually cut narrow to permit better sensation of the ball along the instep. These 
differences in footwear design have been shown to create around $35 \%$ higher forefoot plantar pressures when walking in football boots in comparison to running shoes (Santos et al., 2001). The high plantar pressures seen in football boots are believed to cause an increased risk of metatarsalgia and metatarsal stress fractures (Debiasio et al., 2013; Eils et al., 2004; Queen et al., 2007; Sims et al., 2008; Warden et al., 2007). The incidence rate of metatarsal stress fractures in male professional football was shown to be 0.04 injuries per 1,000 hours (Ekstrand and van Dijk, 2013) - the rate for amateurs is yet unknown. A squad of 25 professional players can therefore expect one stress fracture every third season.

Comfort has been shown to be the most desirable property for football boots in user surveys from 1998, 2006 and 2013 (Hennig, 2014, 2011). Interestingly, injury protection was one of the lowest scoring desired properties (Hennig, 2014, 2011), despite evidence that overuse injuries and footwear comfort in football and rugby are interlinked (Kinchington et al., 2012, 2011). Not only has discomfort been related to increased injury risk, previous studies have linked footwear discomfort to altered lower extremity loading, which consequently triggered muscular fatigue and thereby decreased performance (Kinchington et al., 2012, 2011; Luo et al., 2009). Given the importance placed on comfort by footballers (and the industry in their boot development process) combined with the suggested links with both performance and injury, it is relevant to better understand what objective factors influence comfort perception. In particular, understanding the strength of the relationship between subjective plantar comfort and objective peak plantar pressure data would be of interest and relevant to the football industry.

Comfort can be assessed both from a general (global) overall comfort perception or by focusing on specific local areas. Several studies have attempted to assess both global and local comfort in different footwear types (Che et al., 1994; Dinato et al., 2014; Hinz et al., 2008; Hong et al., 2005; Jordan and Bartlett, 1995; Mills et al., 2011; Mills et al., 2010). Existing research has studied the relationship between objective global and local plantar pressure measures and subjective self-reported comfort perception measures. Studies on running shoes (Che et al., 1994; Dinato et al., 2014; Wegener et al., 2008) and Casual footwear (Jordan and Bartlett, 1995) have attempted to correlate comfort data of both local foot regions and global overall sensation with peak plantar pressures with inconsistent findings.

High plantar pressures are expected to be experienced whilst in-play in football boots compared to these footwear types due to the rapid linear and multi-directional accelerations and decelerations and changes of direction that characterise the game. For football boots, the relationships between plantar pressures and athletic drill (Debiasio et al., 2013; Queen et al., 2007; Sims et al., 2008; Wong et al., 2007), sex (Debiasio et al., 2013; Sims et al., 2008), surface type (Ford et al., 2006), and different boot designs (Bentley et al., 2011; Queen et al., 2008; Santos et al., 2001) have previously been investigated. However, only one study (Nunns et al., 2015) has been conducted on the relationship between objective measures of plantar pressure and subjective data for football boots. The study used football boots with varying added insole cushioning and assessed plantar pressures and subjective comfort rating during football specific movements. Whilst the results indicated that players were capable of sensing some difference in plantar pressures, no statistical analysis was performed on the relationship between plantar pressure and perceived comfort. To further test this indication, the current study was aimed to establish whether the peak plantar pressures during four football specific drills were associated with the subjective measure of footwear comfort. It was hypothesised that using different football boot designs and a spectrum of football specific movements will allow players to detect plantar changes in 
comfort causing a significant relationship between perceived comfort and local peak plantar pressures as well as overall foot global peak plantar pressures.

\section{METHODS}

Ethical approval was obtained from the Loughborough University ethics committee, and voluntary informed consent was obtained from all participants.

\section{Participants}

Eight male university football players participated in the data collection (mean $\pm \mathrm{SD}$, age $=$ $22.1 \pm 3.2$ years; height $=1.76 \pm 0.05 \mathrm{~m}$; mass $=76.08 \pm 4.86 \mathrm{~kg}$ ). No goalkeepers or players suffering from lower limb injuries in the past six months were included. All players wore a UK size 8 and shoe fit was confirmed by palpation for all boots. All players had a neutral static foot alignment, as determined by the Foot Posture Index (Redmond et al., 2006).

\section{Footwear}

Three experimental boots were used (Figure 1): Nike Mercurial Vapor IX FG, Nike HyperVenom Phantom FG, and Adidas F50 Adizero TRX FG. These high-end firm ground boots were chosen due to their popularity; the HyperVenom Phantom FG is a control boot, while the Nike Mercurial Vapor IX FG and Adidas F50 Adizero TRX FG are both lightweight speed boots providing minimal protection. The boots differed in the number, shape and location of studs (as detailed in Figure 1), which was specifically aimed at helping to achieve a wide range of pressures to be experienced by the players. Boots were tested in a randomised order. Players wore the same model of typical football socks and no additional sock liners or insoles were used.

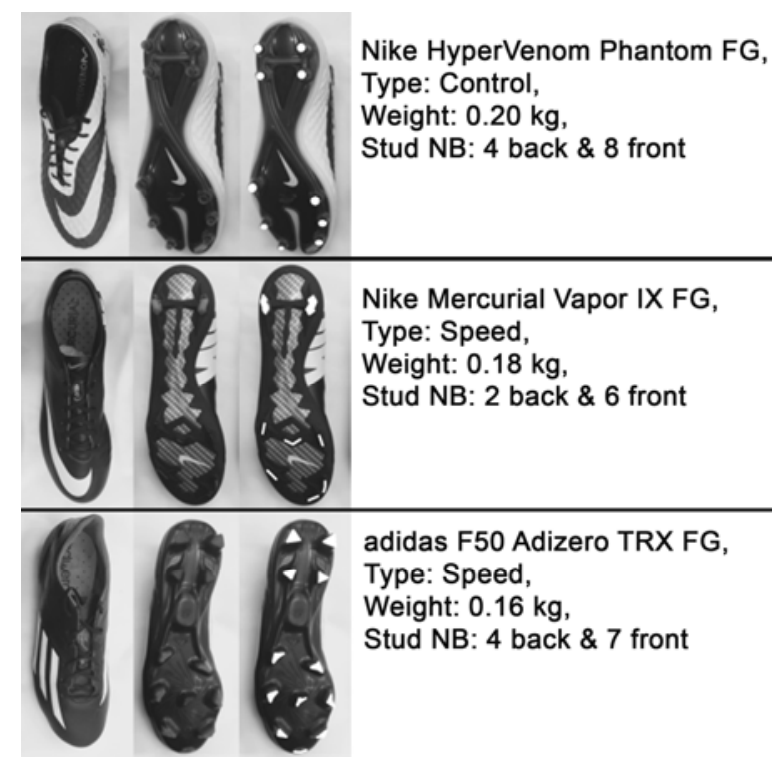

Figure 1: Football boots used. Dorsal view, plantar view, and plantar view with highlighted studs.

\section{Equipment}

A $0.15 \mathrm{~mm}$ thick flexible (type 3000E, $125 \mathrm{psi} / 862 \mathrm{kPa}$ pressure range) Tekscan F-Scan inshoe system sensor (Tekscan, Boston, MA) was fitted and installed in the players' dominant side boot with double-sided adhesive tape to collect plantar pressure data. The plantar pressure data were sampled at $750 \mathrm{~Hz}$. All insoles were equilibrated and calibrated following 
Tekscan official instructions prior to data collection. A Kodak Zx1 High Definition Pocket Video Camera $(720 \mathrm{p}, 30 \mathrm{~Hz})$ was used as reference video with recordings of all drills performed.

\section{Protocol}

The participants were initially taken through a standardised five minute lower limb warm up followed by dynamic stretches as described by Fletcher and Monte-Colombo (2010). Four drills were then completed in the following order (Figure 2):

- Continuous running (mean speed $3.33 \mathrm{~m} . \mathrm{s}^{-1}$ ): 5 stances $\times 2$ repetitions $=10$ stances

- $40 \mathrm{~m}$ maximal effort sprint with $180^{\circ}$ turn (acceleration phase, sprint phase, deceleration phase prior to turn): 3 movements $\times 3$ stances $\times 2$ repetitions $=18$ stances,

- Maximal effort cutting drill (interchanging $45^{\circ}$ side cutting \& $45^{\circ}$ cross cutting with dominant leg): 2 movements $\times 2$ stances $\times 2$ repetitions $=8$ stances,

- Two-footed drop jump landing from $45 \mathrm{~cm}$ height: 1 stance $\times 5$ repetitions $=5$ stances.

Players completed the four drills giving 41 total stances in one boot before changing into another boot type.

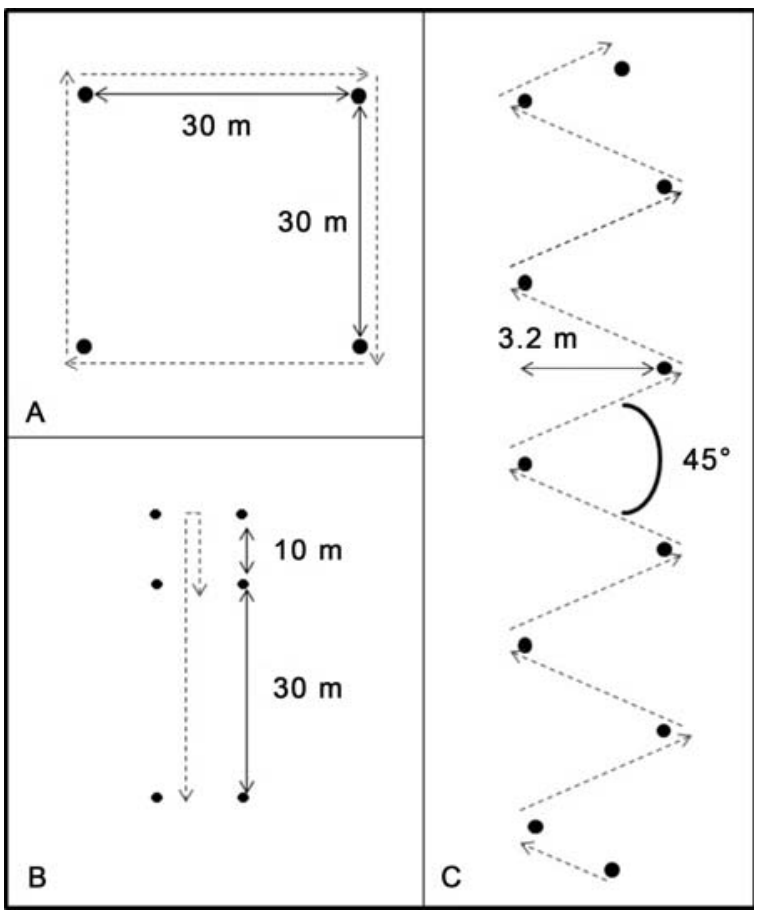

Figure 2: Map of drills used (excluding drop jump landing).

$A=$ straight running at $3.33 \mathrm{~m} \cdot \mathrm{s}^{-1}, \mathrm{~B}=$ Acceleration, sprint, deceleration and $180^{\circ}$ turn followed by acceleration, $\mathrm{C}=$ Cross and side cutting at max effort at $45^{\circ}$ cutting angles.

All drills were performed on a third generation artificial pitch (LigaTurf RS+265, Polytan, Burgheim, Germany). In brief, the pitch had a $25 \mathrm{~mm}$ in situ rubber shockpad, the carpet fibres were $65 \mathrm{~mm}$ monofilament polyethylene and the infill comprised $20 \mathrm{~kg} / \mathrm{m}^{2}$ sand and 12 $\mathrm{kg} / \mathrm{m}^{2}$ rubber crumb giving a total infill height of $37.1 \pm 1.9 \mathrm{~mm}$. Pitch testing conducted immediately after this study using the FIFA Quality Concept methodologies (Fédération Internationale de Football Association, 2010), gave a force reduction of $69.1 \pm 1.0 \%$, vertical deformation of $9.7 \pm 0.5 \mathrm{~mm}$ and rotational resistance of $42.4 \pm 4.2 \mathrm{Nm}$. After completing all 
repetitions of each drill players were asked to fill in a subjective questionnaire consisting of an adjusted $100 \mathrm{~mm}$ visual analogue scale (VAS) for global comfort based on Mündermann et al. (2002), which has shown to be a reliable method to measure subjective plantar comfort in high heel walking (test-retest reliability ICC 0.876, $p<0.01$ ) and basketball footwear testing (test-retest reliability ICC 0.62-0.78) (Hong et al., 2005; Lam et al., 2011). Players were asked to "rate the comfort under the foot by drawing a line on the scale". The left end of the scale was labelled 'not comfortable at all' ( 0 points) and the right end 'most comfortable condition imaginable' (10 points). The points were not shown on the scale but were used when analysing the results following the methodology of Mündermann et al. (2002). Players were also shown an image of the plantar surface of a foot (a foot map, see Figure 3) and were asked to circle locations where discomfort, if any, were experienced during the drill.

\section{Data analysis}

Plantar pressure data was analysed in F-Scan Research 6.60 (Tekscan Inc., Boston, MA). Every stance was evaluated on the reference video by manually matching the stances to the force-time graph in F-Scan Research 6.60 (Tekscan Inc., Boston, MA). Any abnormal movements were excluded from the study. From the continuous jog drill, the five stances were selected after the target speed had been achieved. From the sprint drill, acceleration was taken as the first three stances, sprint stances were taken once the push off force plateaued, and deceleration as the final three stances before the $180^{\circ}$ turn. From the cutting drill, the stance at the extreme position of each cutting movement were selected, excluding the first and last cutting movements of the drill. From two-footed drop jump landing foot contact to the point of peak pressure was analysed. Thus, a total of seven different movements from the four drills were analysed. All plantar pressure data were initially normalised to body weight. The foot was divided into nine foot regions to match the foot map data. This was based on the 12 regions defined by the software followed by a manual grouping of the $2^{\text {nd }}$ and $3^{\text {rd }}$ metatarsal as the medial forefoot, the $4^{\text {th }}$ and $5^{\text {th }}$ metatarsal as the lateral forefoot, and $2^{\text {nd }}$ to $3^{\text {rd }}$ tarsal (figure 3 ). This was done since players often marked a region that covered more than one tarsal / metatarsal on the foot map. Peak plantar pressure was obtained for each selected stance phase over the whole foot and for each of the nine foot region.

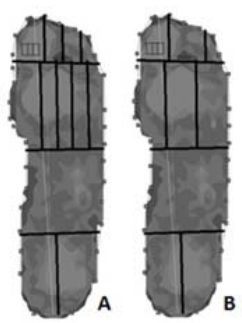

Figure 3: Foot sections used for analysing local perception and local peak plantar pressures. A: Actual foot sections: Medial heel, lateral heel, midfoot, $1^{\text {st }}$ metatarsal, $2^{\text {nd }}$ metatarsal, $3^{\text {rd }}$ metatarsal, $4^{\text {th }}$ metatarsal, $5^{\text {th }}$ metatarsal, hallux, $2^{\text {nd }}$ tarsal, $3^{\text {rd }}-4$ th tarsal, $5^{\text {th }}$ tarsal. B: Merged foot sections: Medial heel, lateral heel, midfoot, medial forefoot, central forefoot, lateral forefoot, hallux, $2^{\text {nd }}-3^{\text {rd }}$ tarsal, $4^{\text {th }}-5^{\text {th }}$ tarsal.

Statistical analysis was conducted in Statistical Package for the Social Sciences Software (SPSS) version 19 (SPSS Inc., Chicago, Illinois). Significance was set at $\mathrm{p}<0.05$. Correlation between the global peak plantar pressure over the entire foot obtained from a specific movement in each boot condition and matching VAS scores of overall comfort were 
determined using a Spearman's correlation. Spearman's correlation was used since VAS scale data obtained violated the normal distribution assumption for parametric tests for the whole foot plantar pressure and VAS scale outcomes. Binary logistic regression (Brace, 2012) was performed to compare peak plantar pressure of each of the nine local foot region obtained from a specific movement in each boot condition (the predictor variable) and the foot discomfort map (the dependent variable).

\section{RESULTS}

A total of 984 stances, from all eight participants performing seven different movements (generating 41 stances) in three boots, were analysed. A wide range of global peak pressures were obtained though the variety of drills and boots (example demonstrated in table 1). A weak $\left(r_{s}=-0.126\right)$ yet significant $(p<0.05)$ correlation was shown between the whole foot peak plantar pressure experienced during the recorded stances and the VAS rated comfort (figure 3). The negative correlation demonstrated that an increase in global peak pressure related to a small decrease in global comfort.

Table 1: Global peak pressure range experienced for each participant and mean minimum and maximum peak pressure

\begin{tabular}{lccccccccc}
\hline $\begin{array}{l}\text { Peak pressure } \\
\left(\mathrm{kPa} \cdot \mathrm{BW}^{-1}\right)\end{array}$ & 1 & 2 & 3 & 4 & 5 & 6 & 7 & 8 & Mean $\pm \mathrm{SD}$ \\
\hline Min & 2.8 & 2.6 & 3.1 & 4.3 & 2.2 & 3.8 & 2.9 & 2.6 & $3.0 \pm 0.7$ \\
Max & 10.4 & 10.3 & 9.1 & 9.9 & 13.2 & 11.6 & 11.2 & 10.9 & $10.8 \pm 1.2$ \\
\hline Min = minimal peak pressure experienced, & $\begin{array}{l}\text { Max } \\
\text { standard deviation }\end{array}$
\end{tabular}

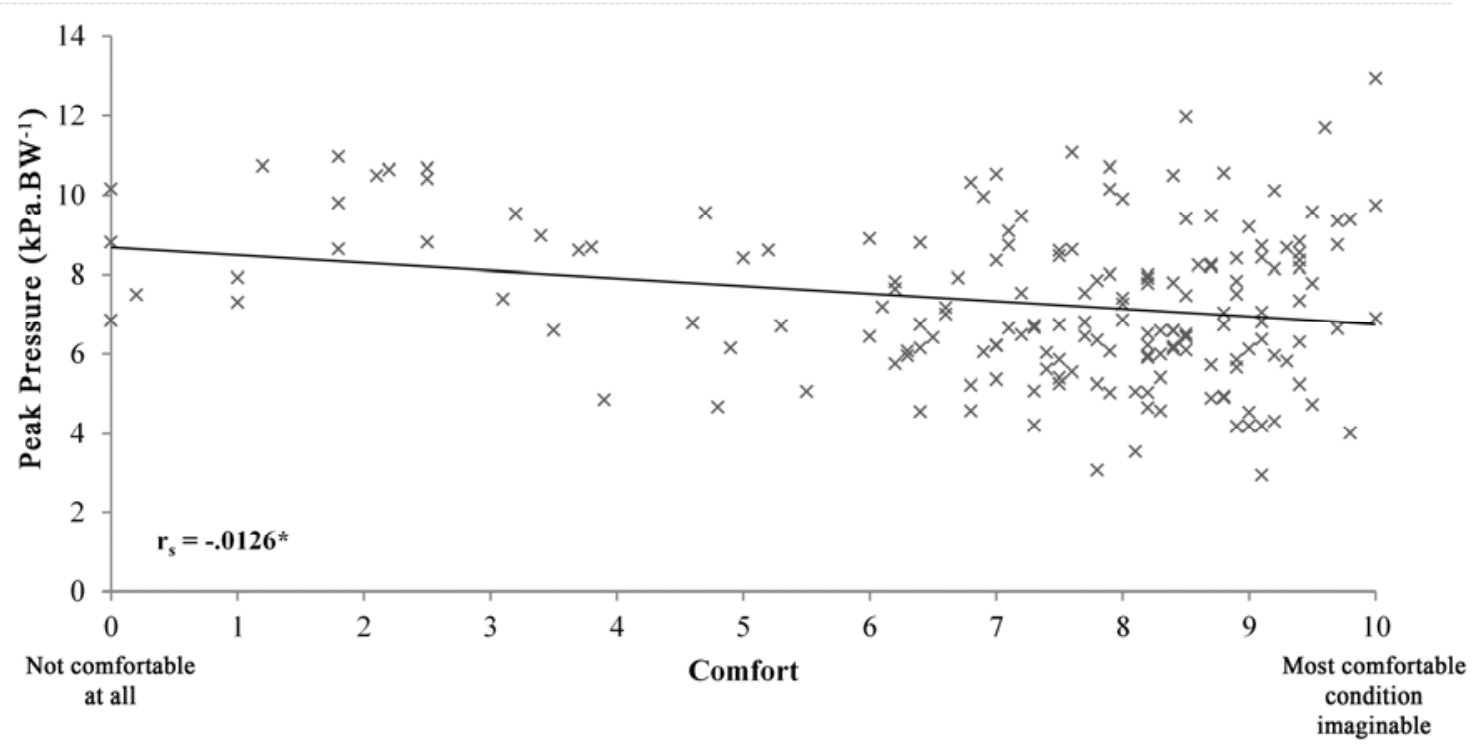

Figure 4: Correlation between outcome of the VAS comfort scale and peak pressure over the entire foot. $r_{s}=$ spearman's correlation.

With the foot divided into nine foot sections, 1,512 local peak plantar pressure measures were compared to the plantar discomfort experienced (yes/no) collected from each player, a total count of 79 discomforts was marked by the players. The omnibus chi-square demonstrates that only discomfort markings at the medial and lateral forefoot significantly predicted $(p<0.001)$ the peak plantar pressure outcome from the nine foot regions (table 2$)$. 
The binary logistic regression model accounted for between 8.0 and $25.8 \%$ of the variance in plantar discomfort experienced for the medial forefoot and between 9.0 and $22.9 \%$ for the lateral forefoot. The central forefoot and lateral heel showed a model accountancy of up to 12.4 and $14.1 \%$ respectively, but with very low $\mathrm{R}^{2}$ lower barriers. For the other foot regions poor fit was shown between the model and the recorded data. Notably, the model predicted $25 \%$ of actual discomforts at the lateral forefoot whereas the model was unable to predict discomforts in any other foot region.

Table 2: Binary logistic regression outcome for foot map markings and local peak plantar pressures.

\begin{tabular}{|c|c|c|c|c|c|c|c|}
\hline & $\begin{array}{l}\text { Omnibus } \\
\text { Chi-square }\end{array}$ & B & S.E. & $\mathrm{R}^{2}(\%)$ & $\begin{array}{c}\text { Correctly } \\
\text { predicted } \\
(\%)\end{array}$ & $\begin{array}{l}\text { Discomforts } \\
\text { predicted } \\
(\%)\end{array}$ & $\begin{array}{l}\text { Discomforts } \\
(\mathrm{N})\end{array}$ \\
\hline Hallux & 2.49 & 0.153 & 0.097 & $1.4-2.8$ & 89.2 & 0 & 22 \\
\hline $\begin{array}{l}2^{\text {nd }}, 3^{\text {rd }}, 4^{\text {th }} \\
\text { tarsal }\end{array}$ & 0.10 & -0.198 & 0.634 & $0.1-0.5$ & 98.9 & 0 & 2 \\
\hline $5^{\text {th }}$ tarsal & 0.89 & -0.180 & 0.616 & $0.1-0.3$ & 97.7 & 0 & 4 \\
\hline $\begin{array}{l}\text { Medial } \\
\text { forefoot }\end{array}$ & $14.61^{\star \star *}$ & 0.716 & 0.216 & $8.0-25.8$ & 94.9 & 0 & 17 \\
\hline $\begin{array}{l}\text { Central } \\
\text { forefoot }\end{array}$ & 2.57 & 0.890 & 0.562 & $1.4-12.4$ & 98.9 & 0 & 4 \\
\hline $\begin{array}{l}\text { Lateral } \\
\text { forefoot }\end{array}$ & $16.54^{\star \star \star}$ & 0.649 & 0.169 & $9.0-22.9$ & 94.9 & 25 & 17 \\
\hline Midfoot & 0.49 & 0.346 & 0.468 & $0.3-1.4$ & 97.7 & 0 & 8 \\
\hline Medial heel & 2.31 & 0.414 & 0.277 & $1.3-8.2$ & 98.3 & 0 & 3 \\
\hline Lateral heel & 2.93 & 0.582 & 0.350 & $1.6-14.1$ & 98.9 & 0 & 2 \\
\hline
\end{tabular}

\section{DISCUSSION}

The aim of this study was to compare local and global peak plantar pressure data with subjective VAS comfort scale data and foot map marking of plantar discomfort. This was done to understand if subjective data can be used as a reliable indicator of increased local pressures. The hypothesis that a correlation exists was only weakly supported. A weak negative correlation $(p<0.05)$ was seen between overall plantar comfort and the peak plantar pressure experienced. The relationship between foot map marking of plantar discomforts and locations of increased plantar pressures showed no relationship for most foot regions and only weak relationships at the medial and lateral forefoot regions.

It was demonstrated by Santos et al. (2001) that higher plantar pressures occur when wearing football boots in comparison to running shoes due to the decreased plantar surface area in the football boot. Other varying factors between football boots and running shoes include the built-in cushioning in running shoes as well as the traction features required for football boots due to the more multi-directional manoeuvres performed. It was therefore expected that the range of comfort values obtained in this study using football boots and football movements would be greater than in the previous study of Dinato et al. (2014) who used running shoes. In contrast to the hypothesis, a widely distributed weak correlation was also observed in this study, indicating that players were unable to detect overall changes in plantar pressures through comfort. A direct comparison of the achieved plantar pressures between studies was not possible as Dinato et al. (2014) did not normalise their peak plantar pressure results with the person's body weight. But with a mean participant body mass of $76.1 \pm 9.2 \mathrm{~kg}$, the peak pressures achieved in the study varied between 1.63 and 4.13 
$\mathrm{kPa} . \mathrm{BW}^{-1}$, which is considerably lower than the pressure range seen in this study (table 1 ). Also, mean peak pressures obtained during the sports specific tasks in the football boots were notably higher with a mean of $7.07 \pm 1.86 \mathrm{kPa}$ BW $^{-1}$.

Previous research has been inconsistent in its conclusion on the relationship between comfort and plantar pressures. Jordan and Bartlett (1995) found no relationship when assessing walking in casual footwear, whilst Che et al. (1994) did find a relationship between the integral and the peak of pressure and comfort feedback when walking in running shoes. However, comfort feedback when running in running shoes did not show sensitivity to plantar pressure changes (Braunstein et al., 2015; Che et al. 1994; Dinato et al. 2014; and Wegener et al., 2008). Indeed, Braunstein et al. (2015) and Dinato et al. (2014), who used similar methods to the current study, found no correlation between local plantar pressures and subjective comfort measures in running shoes. The ability to detect higher plantar pressures in local regions by using a discomfort map in this study was also found to be very poor. Therefore, despite experiencing a wide range of peak plantar pressures experienced across the different boot and various movement tasks, participants were still unable to detect increased plantar discomfort resulting from increased plantar pressures. Despite hypothesizing a significant relationship between local peak plantar pressures and comfort for football boots, only the medial and the lateral forefoot region showed significant correlations in this study. The inconsistency in previous research, in combination with the current results, indicates that plantar comfort rating is a poor predictor of increased local plantar pressures yet overall comfort is still weakly related to peak plantar pressures. It is expected that other factors, such as high shear forces on the plantar surface or discomfort in other areas of the foot, may also have affected the players' rating of plantar comfort. It therefore seems essential that research on new developed football boot designs, conducted to show the boot is superior or fit for purpose prior to launch, includes a thorough investigation of plantar pressure measures to identify potential high-pressure areas and thereby minimise the risk of metatarsalgia and stress fractures (Bennell et al., 1996; Warden et al., 2007). Previous research on comfort in football boots has suggested a multi-faceted approach to assess footwear. It has been suggested that a combination of mechanical, perception and biomechanical assessment is needed for a holistic understanding of boot performance (Nunns et al., 2015). The results obtained in this study support the need for a multi-faceted approach. Furthermore, despite evidence for relationships between the comfort, injury prevention and performance characteristics of a football boot (Kinchington et al., 2012, 2011; and Luo et al., 2009), it appears that these relationships may not be strong enough to allow any category to be neglected in the assessment of the boot.

Previous research has found that wearing Tekscan F-Scan in-shoe system sensors (Tekscan, Boston, MA) alters gait characteristic during running (Kong and De Heer, 2009) and that their durability is limited to a single test session (El Kati, 2010). Based on these findings, and to optimise validity of the pressure data in this study, the sensors were cut to fit the actual shape of each boot and attached to the insole using double-sided adhesive tape (as suggested by El Kati et al., 2010). In addition, each sensor was only used once (i.e. for one boot and player), and the recommended sensor equilibration and calibration techniques were rigorously adhered to. Previous studies used sensors which were non-adjustable standard insole shapes and the fit inside a slim football boot is therefore not optimal and may impact pressure measures at the periphery, which are the zones with higher risks of metatarsalgia (Ekstrand and van Dijk, 2013). Additionally, measuring comfort with plantar pressure in-shoe system sensors would naturally alter the sensation due to the added layer. It can be argued that measuring with a Tekscan F-Scan in-shoe system sensor (Tekscan, 
Boston, MA) of $0.15 \mathrm{~mm}$ thickness in comparison to the $1.9 \mathrm{~mm}$ Pedar (Novel, St. Paul, MN) insole sensor and the $2 \mathrm{~mm}$ EMED (Novel GmbH, Munich, Germany) insole sensor would be more valid. Despite attempting to optimise the validity by minimising the impact from the insole sensor then only weak relationships were observed.

Finally, players only wore the football boots for a short duration (30 min per football boot). This timespan was only sufficient to capture discomforts originating from the players immediate (short term) reaction to the boot. Had the study focused on longer duration wear then different results may have been obtained. Longer duration may also have greater relevance when considering overuse injuries such as stress fractures and metatarsalgia which occur due to repeated long term microtrauma (Ekstrand and van Dijk, 2013). Thus, although the short term comfort response of the player is relevant to the football boot industry, longer term comfort may have more relevance from an injury perspective and may have yielded a stronger correlation with peak plantar pressure.

In conclusion, this study demonstrated that subjective comfort data is not a reliable measure of increased plantar pressures for any foot region. Only a weak correlation was seen between peak plantar pressure of the entire foot and overall perception of comfort. It is therefore important that research include plantar pressure distribution measures when developing new football boot designs as a safety measure to prevent metatarsalgia aggravating locations.

\section{CONFLICT OF INTEREST}

The authors have not received funding from any organization and the authors have no conflict of interest.

\section{REFERENCES}

Bennell, K.L., Malcolm, S.A., Wark, J.D., Brukner, P.D., 1996. Models for the pathogenesis of stress fractures in athletes. Br. J. Sports Med. 30, 200-204.

Bentley, J.A., Ramanathan, A.K., Arnold, G.P., Wang, W., Abboud, R.J., 2011. Harmful cleats of football boots: a biomechanical evaluation. Foot Ankle Surg. Off. J. Eur. Soc. Foot Ankle Surg. 17, 140-144. doi:10.1016/j.fas.2010.04.001

Brace, N., 2012. Bivariate and multiple regression, in: SPSS for Psychologists. Palgrave Macmillan, Basingstoke, pp. 253-292.

Braunstein, B., Schulze, N., Sanno, M., Brüggemann, G.-P., 2015. Comfort and plantar pressure pattern during running with prefabricated insoles. 33rd Int. Conf. Biomech. Sports 932-935.

Che, H., Nigg, B.M., de Koning, J., 1994. Relationship between plantar pressure distribution under the foot and insole comfort. Clin. Biomech. 9, 335-341. doi:10.1016/02680033(94)90062-0

Chen, H., Nigg, B.M., Hulliger, M., de Koning, J., 1995. Influence of sensory input on plantar pressure distribution. Clin. Biomech. Bristol Avon 10, 271-274.

Debiasio, J.C., Russell, M.E., Butler, R.J., Nunley, J.A., Queen, R.M., 2013. Changes in plantar loading based on shoe type and sex during a jump-landing task. J. Athl. Train. 48, 601-609. doi:10.4085/1062-6050-48.3.08

Dinato, R.C., Ribeiro, A.P., Butugan, M.K., Pereira, I.L.R., Onodera, A.N., Sacco, I.C.N., 2014. Biomechanical variables and perception of comfort in running shoes with different cushioning technologies. J. Sci. Med. Sport Sports Med. Aust. 18, 93-97. doi:10.1016/j.jsams.2013.12.003 
Eils, E., Streyl, M., Linnenbecker, S., Thorwesten, L., Völker, K., Rosenbaum, D., 2004. Characteristic plantar pressure distribution patterns during soccer-specific movements. Am. J. Sports Med. 32, 140-145.

Ekstrand, J., van Dijk, C.N., 2013. Fifth metatarsal fractures among male professional footballers: a potential career-ending disease. Br. J. Sports Med. 47, 754-758. doi:10.1136/bjsports-2012-092096

Fédération Internationale de Football Association, 2010. FIFA Quality Concept for Football Turf. Retrieved from http://www.fifa.com/mm/document/ afdeveloping/pitchequip/fqc_football_turf_folder_342.pdf. (Accessed on 24/02/2014).

Fletcher, I.M., Monte-Colombo, M.M., 2010. An Investigation into the Effects of Different Warm-Up Modalities on Specific Motor Skills Related to Soccer Performance: J. Strength Cond. Res. 24, 2096-2101. doi:10.1519/JSC.0b013e3181e312db

Ford, K.R., Manson, N.A., Evans, B.J., Myer, G.D., Gwin, R.C., Heidt, R.S., Jr, Hewett, T.E., 2006. Comparison of in-shoe foot loading patterns on natural grass and synthetic turf. J. Sci. Med. Sport Sports Med. Aust. 9, 433-440. doi:10.1016/j.jsams.2006.03.019

Hennig, E.M., 2014. Plantar pressure measurements for the evaluation of shoe comfort, overuse injuries and performance in soccer. Footwear Sci. 6, 119-127. doi:10.1080/19424280.2013.873486

Hennig, E.M., 2011. The Influence of Soccer Shoe Design on Player Performance and Injuries. Res. Sports Med. 19, 186-201. doi:10.1080/15438627.2011.582823

Hinz, P., Henningsen, A., Matthes, G., Jäger, B., Ekkernkamp, A., Rosenbaum, D., 2008. Analysis of pressure distribution below the metatarsals with different insoles in combat boots of the German Army for prevention of march fractures. Gait Posture 27, 535538. doi:10.1016/j.gaitpost.2007.06.005

Hong, W.-H., Lee, Y.-H., Chen, H.-C., Pei, Y.-C., Wu, C.-Y., 2005. Influence of heel height and shoe insert on comfort perception and biomechanical performance of young female adults during walking. Foot Ankle Int. Am. Orthop. Foot Ankle Soc. Swiss Foot Ankle Soc. 26, 1042-1048.

Jordan, C., Bartlett, R., 1995. Pressure distribution and perceived comfort in casual footwear. Gait Posture 3, 215-220. doi:10.1016/0966-6362(96)82850-5

Kinchington, M.A., Ball, K.A., Naughton, G., 2012. Relation between lower limb comfort and performance in elite footballers. Phys. Ther. Sport Off. J. Assoc. Chart. Physiother. Sports Med. 13, 27-34. doi:10.1016/j.ptsp.2011.02.001

Kinchington, M.A., Ball, K.A., Naughton, G., 2011. Effects of footwear on comfort and injury in professional rugby league. J. Sports Sci. 29, 1407-1415. doi:10.1080/02640414.2011.593041

Kong, P.W., De Heer, H., 2009. Wearing the F-Scan mobile in-shoe pressure measurement system alters gait characteristics during running. Gait Posture 29, 143-145. doi:10.1016/j.gaitpost.2008.05.018

Lam, W.K., Sterzing, T., Cheung, J.T.-M., 2011. Reliability of a basketball specific testing protocol for footwear fit and comfort perception. Footwear Sci. 3, 151-158. doi:10.1080/19424280.2011.630680

Luo, G., Stergiou, P., Worobets, J., Nigg, B., Stefanyshyn, D., 2009. Improved footwear comfort reduces oxygen consumption during running. Footwear Sci. 1, 25-29. doi:10.1080/19424280902993001

Miller, J.E., Nigg, B.M., Liu, W., Stefanyshyn, D.J., Nurse, M.A., 2000. Influence of foot, leg and shoe characteristics on subjective comfort. Foot Ankle Int. Am. Orthop. Foot Ankle Soc. Swiss Foot Ankle Soc. 21, 759-767. 
Mills, K., Blanch, P., Vicenzino, B., 2011. Influence of contouring and hardness of foot orthoses on ratings of perceived comfort. Med. Sci. Sports Exerc. 43, 1507-1512. doi:10.1249/MSS.0b013e31820e783f

Mills, K., Blanch, P., Vicenzino, B., 2010. Identifying Clinically Meaningful Tools for Measuring Comfort Perception of Footwear. [Miscellaneous Article]. Med. Sci. Sports Exerc. Oct. 2010 42, 1966-1971. doi:10.1249/MSS.0b013e3181dbacc8

Mündermann, A., Nigg, B.M., Stefanyshyn, D.J., Humble, R.N., 2002. Development of a reliable method to assess footwear comfort during running. Gait Posture 16, 38-45.

Mündermann, A., Stefanyshyn, D.J., Nigg, B.M., 2001. Relationship between footwear comfort of shoe inserts and anthropometric and sensory factors. Med. Sci. Sports Exerc. 33, 1939-1945.

Nigg, B.M., Nurse, M.A., Stefanyshyn, D.J., 1999. Shoe inserts and orthotics for sport and physical activities. Med. Sci. Sports Exerc. 31, S421-428.

Nunns, M.P.I., Dixon, S.J., Clarke, J., Carré, M., 2015. Boot-insole effects on comfort and plantar loading at the heel and fifth metatarsal during running and turning in soccer. J. Sports Sci. 0, 1-8. doi:10.1080/02640414.2015.1069378

Queen, R.M., Charnock, B.L., Garrett, W.E., Jr, Hardaker, W.M., Sims, E.L., Moorman, C.T., 3rd, 2008. A comparison of cleat types during two football-specific tasks on FieldTurf. Br. J. Sports Med. 42, 278-284; discussion 284. doi:10.1136/bjsm.2007.036517

Queen, R.M., Haynes, B.B., Hardaker, W.M., Garrett, W.E., Jr, 2007. Forefoot loading during 3 athletic tasks. Am. J. Sports Med. 35, 630-636. doi:10.1177/0363546506295938

Redmond, A.C., Crosbie, J., Ouvrier, R.A., 2006. Development and validation of a novel rating system for scoring standing foot posture: the Foot Posture Index. Clin. Biomech. Bristol Avon 21, 89-98. doi:10.1016/j.clinbiomech.2005.08.002

Reinschmidt, C., Nigg, B.M., 2000. Current issues in the design of running and court shoes. Sportverletz. Sportschaden Organ Ges. Für Orthop.-Traumatol. Sportmed. 14, 71-81.

Santos, D., Carline, T., Flynn, L., Pitman, D., Feeney, D., Patterson, C., Westland, E., 2001. Distribution of in-shoe dynamic plantar foot pressures in professional football players. The Foot 11, 10-14. doi:10.1054/foot.2000.0640

Sims, E.L., Hardaker, W.M., Queen, R.M., 2008. Gender differences in plantar loading during three soccer-specific tasks. Br. J. Sports Med. 42, 272-277. doi:10.1136/bjsm.2007.042432

Warden, S.J., Creaby, M.W., Bryant, A.L., Crossley, K.M., 2007. Stress fracture risk factors in female football players and their clinical implications. Br. J. Sports Med. 41, i38-i43. doi:10.1136/bjsm.2007.037804

Wegener, C., Burns, J., Penkala, S., 2008. Effect of Neutral-Cushioned Running Shoes on Plantar Pressure Loading and Comfort in Athletes With Cavus Feet A Crossover Randomized Controlled Trial. Am. J. Sports Med. 36, 2139-2146. doi:10.1177/0363546508318191

Williams, A.E., Nester, C.J., 2006. Patient perceptions of stock footwear design features. Prosthet. Orthot. Int. 30, 61-71.

Wong, P., Chamari, K., Mao, D.W., Wisløff, U., Hong, Y., 2007. Higher plantar pressure on the medial side in four soccer-related movements. Br. J. Sports Med. 41, 93-100. doi:10.1136/bjsm.2006.030668 